\title{
Novo Titular da Cadeira de Direito Administrativo - Prof. J. Cretella Júnior
}

O Professor Cretella Júnior, filho de José Cretella e da professora Maria José Loureiro Cretella, nasceu em Sorocaba, no dia 10 de janeiro de 1920.

Fêz o curso primário, em Santos, na Escola "Barão do Rio Branco" e o curso secundário no tradicional Ginásio do Estado, diplomando-se em 1938.

Em 1939, ingressou para a Faculdade de Filosofia, Ciências e Letras de S. Paulo, freqüentando a Seção de Letras Clássicas e Português, licenciando-se em 1941, ao mesmo tempo que concluiu o curso de Didática Geral e Especial, na mesma Faculdade.

Posteriormente, cursou a Faculdade de Direito de S. Paulo, alcançando o 1. ${ }^{\circ}$ lugar, nos exames vestibulares e concluindo o curso em 1950. Por essa ocasião conquistou o Prêmio "João Arruda", conferido pelo Prof. Miguel Reale, a quem apresentou os trabalhos Relação entre vigência $e$ eficácia no direito positivo e Interpretações do fenômeno jurídico.

Foi premiado duas vêzes pelo Instituto dos Advogados de S. Paulo, primeiro com o trabalho original "Natureza jurídica do contrato de esporte", depois com o tratado "Direito Administrativo do Brasil".

Prestou seis concursos para o magistério desde 1941, tendo sido aprovado, primeiro, no concurso de Português para a Escola de Preparatórios de Cadetes do Exército, a seguir (1943), no concurso de Latim para o Ensino Secundário, quando obteve média final 10 (dez) entre 73 concor- 
rentes. Em 1965, com a tese Do desvio de poder obteve a livre-docência de Direito Administrativo da Faculdade de Direito de S. Paulo com distinção e, em 1969, conquistou a cadeira de Direito Administrativo da mesma Faculdade, vaga com a aposentadoria do Prof. Mário Masagão, tendo sido aprovado por unanimidade em Banca integrada pelo Prof. Miguel Reale, magnífico reitor da Universidade de S. Paulo, Prof. Sílvio Rodrigues, titular de Direito Civil, Desembargador M. Seabra Fagundes, Prof. Caio Tácito da Faculdade de Direito da Guanabara e Franco Sobrinho da Faculdade de Direito do Paraná.

\section{Bibliografia}

a seguinte a bibliografia do prof. Cretella Júnior.

a) De Direito Administrativo.

1. Da codificação do direito administrativo, S. Paulo, 1951.

2. Natureza jurídica da função pública, S. Paulo, 1953.

3. Do desvio de poder, S. Paulo, 1965.

4. Dos bens públicos no direito Brasileiro, S. Paulo, 1969.

5. Direito administrativo do Brasil, S. Paulo, Revista dos Tribunais, 1956-1962 (5 volumes, alguns em 2. ${ }^{a}$ edição).

6. Tratado de direito administrativo, Rio, Editora Forense, 1966/1970 (10 volumes, dos quais 8 já publicados).

7. Direito administrativo, S. Paulo, Revista dos Tribunais, 1963 (esgotado).

8. Curso de direito administrativo, Rio, 1967, Editora Forense.

9. Regime jurídico do pessoal extranumerário, S. Paulo, 1962. 
10. Les fondations de droit public au Brésil, S. Paulo, 1963.

11. Fundações de direito público, na Revista da Faculdade de Direito de S. Paulo, n. de 1966.

12. Regime jurídico das fundações públicas, no Brasil, em RDA 89.

13. Regime jurídico das corporações públicas, no Brasil em RDA 98.

14. Principios informativos do direito administrativo, em PDA 93.

15. As categorias jurídicas e o direito público.

16. Executoriedade do ato administrativo unilateral, em RDA 71.

17. A "via de fato" no direito administrativo, em RF 205.

18. A teoria do "fato do príncipe", em RDA 75.

19. O mérito do ato administrativo, em $\mathrm{RF} 209$.

20. A "exceptio non adimpleti contractus", no direito administrativo, em RDA 82.

21. Empréstimo compulsório é contrato de direito público, em RDA 83 e RF 214.

22. Anulaçâo do ato administrativo por "desvio de poder", em RDA 92.

b) Outros Trabalhos.

23. Português para o ginásio ( $\left(.^{\mathrm{a}}\right.$ série).

24. Português para o ginásio (2. ${ }^{\mathrm{a}}$ série).

25. Português para o ginásio ( $3 .^{\mathrm{a}}$ série).

26. Português para o ginásio ( $\left(.^{\mathrm{a}}\right.$ série).

27. Literatura para o colégio $\left(1 .^{\mathrm{a}}, 2 .^{\mathrm{a}}\right.$ e $3 .^{\mathrm{a}}$ séries $)$.

28. Latim Colegial (3 séries).

29. Gramática de língua grega (1940).

30. Glossário da língua arcaica portuguêsa.

31. Dicionário latino-português.

32. Manual prático de pronunciação latina (1943).

33. Quadros de declinação latina (1942).

34. A poesia de Augusto dos Anjos. 
35. Novissima História da Filosofia (1967).

36. Curso de Filosofia do Direito (1967).

37. Dicionário de direito do trabalho (1951).

38. Curso de direito romano (1967).

\section{Posse da cátedra de Direito Administrativo}

Com os títulos mencionados submeteu-se o prof. Cretella Júnior ao concurso de Direito Administrativo, sendo argüido e aprovado unânimemente pela Comissão Examinadora sôbre a tese Dos bens públicos no direito brasileiro, monografia de 400 páginas.

Nomeado, tomou posse em sessão solene da Congregação, realizada no Salão Nobre da Faculdade, em sessão presidida pelo Sr. Diretor, Prof. Dr. J. Pinto Antunes, a 22 de dezembro de 1969.

Introduzido no recinto pelos professôres eméritos Mário Masagão, Ernesto Leme e Noé Azevedo, foi saudado em nome da Congregação pelo Prof. Dr. José Carlos de Ataliba Nogueira.

\section{Saudação do Professor Ataliba Nogueira}

"Há vinte anos, mais dia menos dia, talvez como mero sonho, imaginastes esta solenidade: reunir-se a congregação, em que vários dos catedráticos foram vossos mestres, para receber-vos festivamente; alegres e prazerosos ouvirem vosso compromisso de servir a mocidade, de contribuir para a maior grandeza da Academia e de conviver conosco.

Não deixou de ser a escalada da montanha o longo caminho percorrido. Deu-vos, porém, muito maior enlêvo e a certeza de que não foram em vão os dias trabalhosos dêstes dilatados anos, as vigílias, o desassossêgo, o sacrifício, o propósito cumprido do "nulla dies sine linea". 


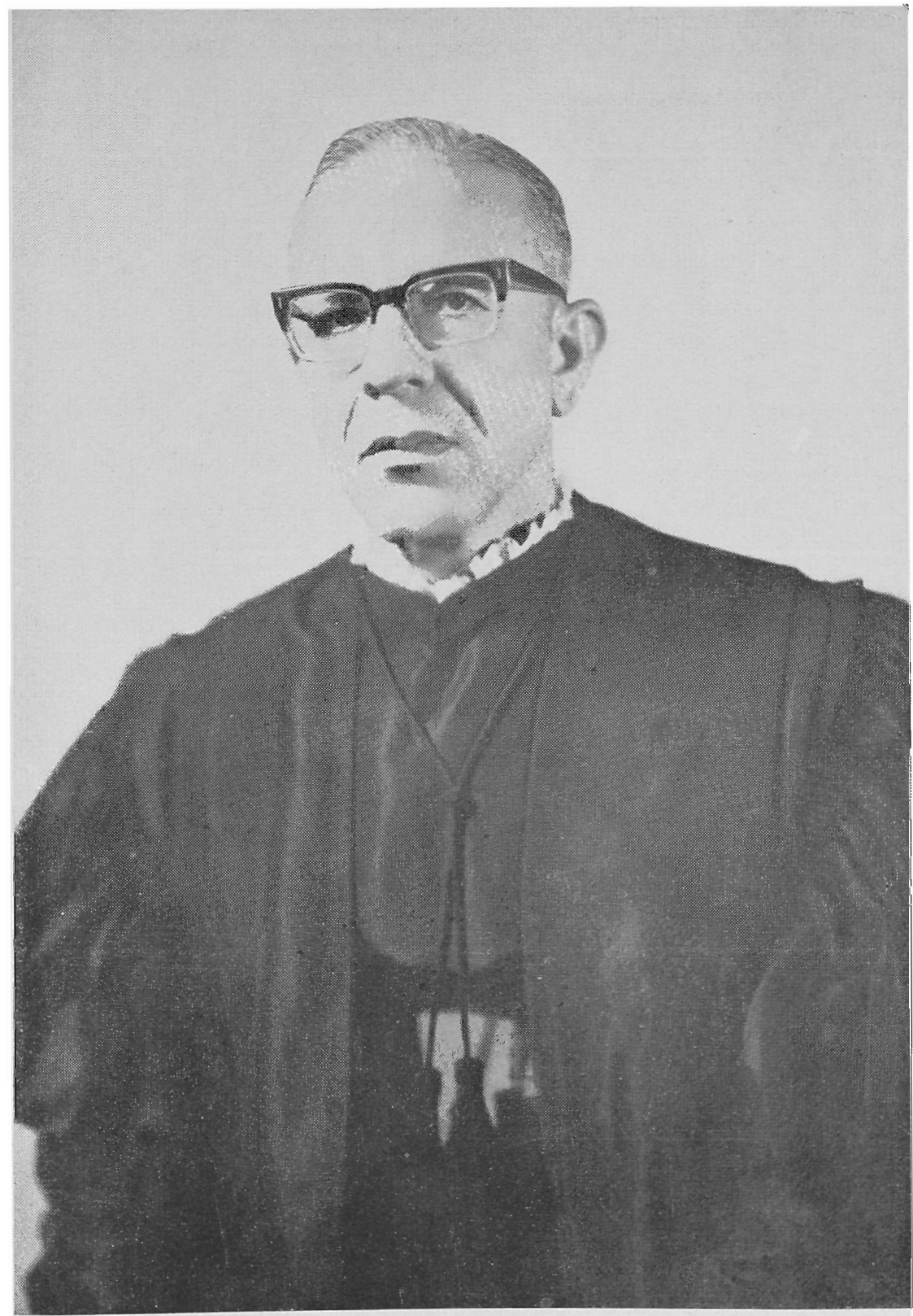

Prof. José CRETELLA JÚNIOR.

Nôvo titular da Cadeira de Direito Administrativo, 
Foi assim a vossa vida intelectual, sem deixar de lado as ocupações de cada dia, o labor incessante do chefe de família. Nobre exemplo aos moços de que é possível sacrificar muitas coisas tão belas para não diminuir as horas de leitura, de estudo, de meditação e de redação dos trabalhos jurídicos. $E$ as jornadas sucediam-se, em longo desfilar, considerando ora a dureza de estilo, ora a obscuridade do raciocínio, ora a inutilidade de doutrinações e classificações de mestres da especialidade. Houve, muitas vêzes é verdade, o prazer de vos defrontardes com páginas maravilhosas de grandes juristas deixando sulco profundo e indelével em vosso espírito.

Ao estudo sucedendo sempre as horas de meditação foi assim que buscastes firmar o conhecimento exato a respeito dos maiores problemas da disciplina. E o prazer de escrever, de divulgar e ensinar aquilo que tanto e tanto vos custou resolver, com próvida emulação do trabalho, reconhecendo o valor da doutrina dos vossos predecessores em tão importantes questões.

Depois de trilhardes a vereda difícil, galgastes o cimo e daqui divisais hoje o sopé. Nada de grande se faz sem trabalho e perseverança. E tais virtudes, ouso dizer, infundiu-vos e vos ajudou a mantê-las varonilmente, e sem eclípse essa doce figura humana, suave e rica de dotes, a sua mulher, dona Agnes.

É assim que interpreto a singela dedicatória deixada por vossas mãos no verso da fôlha de rosto do Tratado de Direito Administrativo.

Forrado de sólida cultura humaná, vos preparastes para a especialização. É o prelúdio remoto indispensável: o conhecimento primoroso do vernáculo, o manuseio diurno e noturno dos bons escritores do idioma pátrio; o gôsto pelo latim só alcançado perfeitamente na convivência de tôda uma civilização; o trato freqüente com várias línguas vivas; por fim, a história e a filosofia. 
Todo êste cabedal não tem sido apenas para vosso uso, como imprescindível instrumento de execução do programa maior. Foi repartido com os adolescentes, os vossos alunos do colégio, que, por sua vez, vos propiciaram a prática pedagógica. Mesmo para o que tem vocação para mestre importa o tirocínio, quer para o trato com os discípulos cuja simpatia e confiança há de granjear; quer para descobrir e aplicar artifícios pedagógicos, tanto mais eficientes quanto mais subtis; quer finalmente para se assenhorear bem da matéria, cujo domínio deve ser completo, embebido nela o mestre como o mata-borrão da tinta.

Já é pois o professor afeito ao difícil mister, que agora sobe à cátedra universitária numa Faculdade em que o ensino tem metodologia especial e que requer acervo das qualidades de professor experiente e eficiente.

Já antes desta confirmação no pôsto máximo da carreira universitária, prova a vossa vida que vos consagráveis totalmente ao ensino. É o melhor augúrio para o êxito do vosso professorado aqui.

Ireis verificar, entretanto, que êste resultado vai igualmente depender dos vossos alunos.

Entre as medidas necessárias ao máximo aproveitamento do ensino ocupa lugar saliente a do tempo integral. Se no tocante aos professôres de matérias de cunho prático, destinada ao exercício de profissões forenses, há sérias restrições, já quanto aos alunos é indispensável a dedicação plena. A própria prática há de estar subordinada à orientação e exercício disciplinados pelos mestres.

Consagrar-se o acadêmico inteiramente ao estudo do direito é a grande inovação necessária. A obrigatoriedade de tempo integral é das maiores diferenças entre o estudante de direito e os outros universitários.

Os alunos de medicina e de engenharia, para sòmente referir os ligados de longa data aos nossos, passam o dia todo na escola ou nas suas dependências, nos hospitais, laboratórios, oficinas, institutos. Muitos acadêmicos de 
direito, ao contrário disto, alegam não haver tempo sequer para ler os livros recomendados, para conversar com o mestre ou os seus assistentes dentro ou fora dos seminários, não haver vagar pelo menos para resumir lições, para elaborar trabalhos escritos, para ordenar outros trabalhos, para folhear autos, para efetuar pesquisas na biblioteca, para assistir às conferências e às festas culturais da Academia.

Limitam-se ao mínimo, às preleções, e, quando reclamam e acoimam de velha e revelha a pedagogia atual, bem diferente aliás da do meu tempo, o que na realidade preconizam é a supressão dêsse mínimo de exigências, as preleções.

Afora o período das oito horas ao meio-dia, para a maior parte dos acadêmicos nada mais resta de dedicação ao conhecimento do direito. $\mathbf{E}$ verdade; esqueci-me do estudo intensivo e estafante das duas semanas antecedentes aos exames!

Senhores: Já foi decretada a reforma da nossa universidade. Estará em vigor dentro em poucos dias. É prevista na nova lei a concessão de bolsas de estudo. Pois que estas se não limitem a tornar gratuito o ensino para os alunos carecentes de meios, mas que resolvam também o problema do tempo integral por parte dos universitários, fornecendolhes o necessário para pagar morada e pensão fora do campus. E, ainda, favorecendo os que escolherem, dentre as numerosas carreiras abertas ao bacharel em direito, as que requerem a prática forense.

Professor Cretella Júnior, sempre afeito às vossas lições, no curso secundário e desejoso do melhor aproveitamento dos seus destinatários, são de vossa lavra numerosos livros didáticos de português e latim, favorecidos com o acolhimento nas escolas em geral.

Em mais de meia centena de vossos artigos em revistas, monografias, opúsculos e obras, diviso também o fruto de lucubrações de ordem literária, de crítica e até mesmo de 
análise de poesias. São de bôa traça, atestados do vosso espírito curioso e incansável.

Predominam, porém, os estudos jurídicos, que vos preocupam precìpuamente, desde que se firmou em vossa vontade a primazia da docência do direito e, neste, a do direito administrativo.

A vocação para mestre desenvolveu-se com a de jurista.

Dou de mão aos frutos ainda não amadurecidos dos đois estudos publicados quando prêso aos bancos escolares, embora hajam merecido láureas acadêmicas de alta significação. A pouco e pouco vão surgindo lavores de maior fôlego, como as vossas dissertações sôbre $A$ codificaçâo do direito administrativo a Natureza jurídica da função pública e Do desvio de poder.

Galardoôu trabalhos de vossa autoria o Instituto dos Advogados de São Paulo, associação tão acatada e prestigiosa entre nós e que acompanha com desvelo a nossa vida jurídica.

Não é de estranhar que logo vos fôssem buscar para o ensino das suas disciplinas as Faculdades de Direito de São José dos Campos e de São Bernardo do Campo.

$\mathrm{E}$ com as monografias surgem os artigos nas revistas e já a obra de maior fôlego, o Direito Administrativo do Brasil, em cinco volumes, levados a cabo em cinco anos.

A quem menos agradou o resultado de tão grande esfôrço, tão bem recebido por tôda parte, foi ao próprio autor.

Por isto, não cuidou de segunda edição, mas de refundir a obra. Abalou por novo caminho, traçando largo plano, excogitando método mais rigoroso, ampliando os assuntos versados, enriquecendo o erudito aparato crítico.

É assim que surge, em 1966, o Tratado de Direito Administrativo, distribuída a matéria por dez volumes, dos quais sete já publicados. 0 primeiro a festejar a nova obra, erudita e útil, foi o nosso brilhante colega, professor $\mathrm{Al}-$ fredo Buzaid, em prefácio assás elogioso. 
Num único volume, em sintese apertada, destes à publicidade um manual das instituições administrativas.

Finalmente, a vossa obra a respeito Dos bens públicos, com que alcançastes ser titular da cadeira que passa a lecionar em caráter efetivo, de hoje em diante.

Do alto conceito que gozam os vossos trabalhos jurídicos, a melhor prova é o número de citações da vossa opinião nêles exaradas por parte de juristas, administrativistas, juízes e advogados.

Por tal motivo é que um dos vossos argüentes, no último concurso, se declarou cauteloso por ter diante de si um tratadista do direito administrativo.

Ides confirmar, professor Cretella Júnior, a galeria dos nossos mestres desta cadeira, nomes respeitáveis, que tanto contribuiram para o elevado conceito que goza a Academia de Direito de São Paulo em todo o Brasil. O vosso antecessor, professor Mário Masagão, formou várias gerações, ministrando-lhes a melhor doutrina.

Ides integrar o nosso Instituto de Direito Público criado pela congregação em 1952.

Com o novo titular de direito constitucional, professor Manoel Gonçalves Ferreira Filho, constituis a fôrça nova, a seiva viva daquela instituição universitária que do modesto orador que vos saúda, outro de seus componentes, só pode, já agora, receber conselhos de prudência e de experiência. Com as dezenas de juristas que o prestigiam e nos ajudam no programa de estudo e renovação do direito público levaremos por diante o Instituto. Seus cursos especiais, conferências, discussão de temas continuarão com os novos titulares, associados ao mais antigo, não medindo esforços todos nós para o trabalho comum.

A época é a mais propícia e justamente agora o Brasil e as letras jurídicas requerem a nossa colaboração. E momento para o Instituto. Não porque haja crise de direito, o que negamos, mas pela renovação enorme dêstes ramos da nossa ordenação jurídica, num mundo que anseia 
por ser nôvo e por ser regido pela justiça. Ora, o direito é o instrumento da realização da justiça, quando os seus sacerdotes o coloquem a serviço da mesma justiça.

No borborinho das agitações, no encontro ou desencontro das idéias, nas vontades que se embatem, na mais suposta que real anarquia, na quebra da placidez, aliás nunca verdadeiramente vivida no passado, o que na realidade vai caminhando a passos seguros mas não aparentes, na era cósmica e neste mundo terráqueo, é a busca de nova ordenação jurídica para reger o mundo nôvo.

E próprio das épocas de mudança radical a confusão e o atabalhoamento, a vivacidade e o vigor, quanta vez despendidos com exagêro e incompatíveis com a serenidade.

É lição da história, única experiência lícita ao político. Aos políticos, e de modo especial aos estadistas, incumbe a tarefa ingente, mas a seu lado e com igual responsabilidade, se bem que circunscritos à sua especialidade, aos juristas.

Aos juristas é que compete aquela tarefa. A economia, as finanças, a técnica, a administração, a própria política, abrem os horizontes novos e nisto se resume o papel dos respectivos cultores. Uma vez apreciadas, medidas e decididas as reformas por parte dos estadistas e ação dos demais políticos, o jurista é que deve redigir as normas jurídicas a serem editadas pelos órgãos do poder público estabelecidos pelo regime democrático. Nêles também há de ter assento, tal incumbência lhe é própria, não apenas por sua técnica especializada, mas ainda pela sua formação moral, pela sua formação intelectual, pela formação total do jurista, pelo modo como considera o homem, pela alta conta em que o tem, pela defesa dos seus direitos fundamentais e inalienáveis sempre presente, pela justiça que lhes é apanágio.

E parte integrante da justiça é a justiça social, que tanto vai mudando a ordenação jurídica do estado por todo o mundo. 
O verdadeiro jurista, em meio aos abusos do direito, à fraude, às violações dos preceitos das normas jurídicas; impressionado pela proliferação do mal, embatido pela violência, abatido pelas manifestações da fôrça, o verdadeiro jurista - diríamos - não pensa um minuto sequer em suprimir o direito em opor-lhe outra violência, em denegrir a justiça.

Senhores :

Não é possível prescindir do calor, ainda que sufoque; nem da água, ainda que inunde; nem do ar, ainda que possa poluir-se; nem da eletricidade, mesmo que abrase. Assim também, o direito há de reger as ações do homem em busca do progresso, da democracia, da justiça social. $\mathrm{O}$ direito é que há de ordenar o futuro dos povos ainda que a sua observância por vêzes pareça comprometer o império do próprio direito.

Por tais razões é que afirmavamos há pouco que à obra grandiosa e patriótica da nossa Academia, em educar e instruir a mocidade e em infundir-lhe o amor ao direito e o religioso respeito à justiça, se junta o Instituto de Direito Público, parte integrante da nossa escola.

Demonstrou conhecer-lhe os méritos, alojando-o adequadamente em salão especial, com biblioteca e instalações próprias, o nosso ilustre colega e diligente diretor da Faculdade, Professor Pinto Antunes.

Professor Cretella Júnior:

Não vos é estranha, pelo contrário, já é também vossa desde o comêço, a Revista de Direito Público. É veículo das atividades do Instituto de Direito Público e instrumento de atuação dos seus membros. Dirigida com competência por dois jovens mestres de direito, nada custa aos cofres públicos, graças à participação, neste empreendimento, da Emprêsa Gráfica da Revista dos Tribunais.

Sente-se feliz a nossa Faculdade ao receber-vos nesta data como professor titular. Aliais ao conhecimento da 
matéria as qualidades didáticas; ao renome conquistado, entusiasmo e vida pujante e comunicativa.

Constitui esta solenidade mais uma renovação do corpo docente. Não é rotina. Interpreto-a como a transmissão de geração a geração daquele fundo imponente, que tem perdurado assim na trajetória grandiosa da escola sempre nova. Os grandes nomes, cheios de saber e ao cabo de uma existência tôda a ela consagrada, vêem com prazer, por isto, o futuro radioso da nossa Academia.

Sim, requer o ensino que se passe, ordinàriamente, das regiões onde brilha a luz das idéias para as regiões onde arde o calor do sentimento e da vida. É o mundo da inteligência e o mundo dos afetos.

Quanto mais temos vivido nesta escola, tanto mais a amamos e quanto mais são os anos que aqui contamos, tanto mais são as razões com que estamos pegados a esta casa.

Deus vos faça muito feliz.

\section{Discurso do nôvo catedratico}

Agradecendo a saudação recebida, o nôvo titular da Cátedra de Direito Administrativo pronunciou o seguinte discurso.

“Quando há poucos dias recebi a notícia de que fôra aprovado no Concurso de Direito Administrativo, fiquei simplesmente aturdido, entre confuso e perplexo, não obstante há quase vinte anos viesse alimentando, dia a dia, minuto a minuto, esta longínqüa, remota esperança, concretizada, afinal, após quatro batalhas difíceis.

Tal estado de espírito se explica, porque, ao ser admitido a êste douto Colégio, compreendi a responsabilidade que me principiava a pesar sôbre os ombros, ao suceder a Mário Masagão, que recebera a herança de Villaboim, o qual, por sua vez, tivera como antecessores, no II. ${ }^{\circ}$ Império, 
nomes da categoria de um Silveira da Mota, de um Ribas, de um Furtado de Mendonça, de um Rubino de Oliveira.

Basta a simples enunciação dêsses nomes, cada qual valendo por todo um título de glórias, para ter-se idéia do extraordinário legado recebido pelo nôvo titular.

Mário Masagão foi professor de nossa turma. Dêle guardo constante lembrança. Mestre preciso, magistrado objetivo, argüente temido nos concursos, deixou profunda impressão de saber e equilíbrio, na memória de seus discípulos.

A êste mestre, aqui presente, que está completando meio século de formatura, rendo meu tributo de admiração e respeito.

A alegria de minha investidura, neste momento, é ainda aumentada com a resolução de nosso operoso diretor, professor Pinto Antunes, designando para saudar-me o inclito mestre Ataliba Nogueira.

Conheço o vosso intérprete, Senhores Professores, há muitos anos, acompanhando-lhe a carreira de professor no Ginásio do Estado, de Promotor Público, de Delegado do Brasil à XII. ${ }^{a}$ Assembléia Geral das Nações Unidas, Deputado Federal por São Paulo, Secretário de Estado, autor das teses Medidas de Segurança, O Estado é meio e não fim, Pena sem prisão.

Afável e compreensivo, sempre me incentivou nos estudos, dando-me estímulo necessário nos momentos difíceis.

Muito grato por suas palavras que muito me emocionaram.

Esta Academia sempre me pareceu algo longinqüo e inconquistável, ideal pràticamente inatingível.

Sabia e sei quantos almejam ingressar neste templo e quão poucos chegam a atingir a meta final.

Quantas vêzes passei pelo Largo de São Francisco e fiquei a contemplar esta Casa, símbolo de um passado imorredouro e histórico! 
Posso olhar para trás e contemplar o extenso caminho percorrido. Estudei todos êstes anos para ter a honra de pertencer ao excelso colégio de juristas, que me recebe com tanto carinho.

Dificuldades sem conta venci. Renunciei a muita coisa, dedicando horas e horas ao estudo, sacrificando o supérfluo para ter à mão as obras mais modernas que apareciam.

Embranqueceram-me os cabelos. Madruguei muitas vêzes, levantando para pesquisar uma idéia, completar um pensamento, rever um dado.

Nesta casa, aprendi a amar o Direito e a cultuar a Tradição.

Academia do Largo do São Francisco!

Que emoção ao chegar. Que sensação indescritivel a de sentar-me ao lado dos colegas ilustres, de passar pelas Arcadas legendárias e augustas, de entrar nas mesmas salas de aula em que fui aluno, de receber todo o impacto histórico-cultural de uma veneranda casa sesquicentenária, de percorrer os saguões, a biblioteca, de contemplar as estátuas que perpetuam os vultos da história pátria. E isso na qualidade de professor, trilhando o mesmo caminho percorrido como estranho, aluno, livre-docente, titular.

$\mathrm{E}$ ter a certeza certa, a vivência viva, de estar integrando a Congregação dêste Templo, escola de civismo que recorda o passado e se projeta para o futuro, com um sentido dinâmico de eterna modernidade.

Desde bem moço interessei-me pela História da Faculdade, colecionando e lendo tudo que se relacionasse com a vida da Academia.

Quantos vultos de primeira grandeza por aqui passaram, vivendo diversos sonhos, alimentando diferentes ideais, mas ligados, todos, por um ponto comum de afeto, a estas sacrossantas paredes, que trescalam cultura e fé nos destinos da pátria.

Acalentei a idéia de entrar para cá, ainda estudante, acompanhando as atividades dos professôres, assistindo aos 
concursos desde 1938, quando aluno do Ginásio do Estado da Capital, discípulo de Cesarino Júnior e colega de Oscar Barreto Filho.

Prometi a mim mesmo não descansar enquanto não lecionasse nesta Escola.

Minha mulher, aluna também desta Faculdade, incentivou-me todo êste tempo, dando-me o ânimo de que necessitava, quando eu esmorecia diante da complexidade dos problemas jurídicos.

Os amigos também me animaram. Vejo-os agora, quase todos, na doutoral e na assistência. Seria arriscado enumerá-los um a um, nominalmente, pela possibilidade involuntária de omissão.

Que cada um aceite de modo especial o meu agradecimento, na proporção exata em que desejou minha vitória.

Divido o resultado com êsses amigos leais que formaram na primeira linha.

Lembro as vêzes inúmeras que recorri ao professor Alfredo Buzaid, coração imenso, aliado a invulgar cultura, que me pôs à disposição sua biblioteca especializada e me apontou o caminho certo, na discussão das grandes teses jurídicas.

Só lamento aqui duas cadeiras vagas, que estariam hoje ocupadas por um casal de velhinhos, meus pais, levados da terra pela justiça divina, mas que me acompanham os passos, guiando-me do alto.

Ouvi atento as palavras do vosso intérprete, sintetizando os votos de boas-vindas ao nôvo colega, submetido à cerimônia de iniciação e aceito.

Trago para esta Casa todo um passado de 30 anos de magistério, lecionando e escrevendo, examinando e sendo examinado em Concursos, procurando aprimorar-me em vários setôres até fixar-me na matéria de minha predileção que é o Direito Administrativo. 
Sou entusiasta dos problemas do ensino e cada aula é para mim fonte constante de sugestões e rejuvenescimento perene.

Deve o professor ser o primeiro aluno de sua turma. Não compreendo o mestre que não aprende algo de nôvo ao preparar sua aula e executá-la, já que o ensinar é um momento único de criação artística e científica, milagre original que nunca mais se repete.

Dediquei a vida ao ensino. Quis entrar para a Academia para serví-la, para trabalhar por ela, dedicando-lhe o melhor de meus esforços.

Nestes cinco anos de livre-docência, mais aprendì do que ensinei. No convívio agradável dos livre-docentes, muitos dos quais já titulares, tive a oportunidade de trocar idéias proveitosas, que me possibilitaram novas perspectivas.

A missão do educador é formar, não apenas informar. Deve-se dar ao jovem mais método do que conteúdo, mais processos de pensar do que um amontoado de fatos, dados, números e datas, suporte apenas do processo mental.

O campo do Direito Administrativo é extraordinàriamente vasto e fascinante.

Há um programa imenso a cumprir, uma problemática nova aberta com a criação de pessoas jurídicas públicas, paraestatais e autárquicas, suscitando novos equacionamentos para a disciplina.

O Direito Administrativo palpita a cada passo, numa transformação acelerada, flexionando-se para a resolução dos casos à luz dos princípios publicísticos, criando-se institutos típicos, inconfundíveis com os paralelos do direito privado.

Multiplicam-se as Emprêsas Públicas. As Fundações de Direito Público são estruturadas e estudadas, procurando-se estabelecer seu regime jurídico. Cria-se o Contencioso Administrativo. 
Os Bens Públicos revelam aspectos que merecem a maior atenção dos juristas, que se voltam para êste setor fecundíssimo do direito. Vivemos uma época de grande renovação cultural. A Universidade de S. Paulo é modêlo para tôda a América Latina.

A publicação do Nôvo Estatuto da Universidade descortina extraordinário campo para o ensino superior e abre horizontes imensos para a pesquisa, a tecnologia, a investigação pura. $\mathrm{E}$ inestimável foi a contribuição desta Casa para tão alta realização.

Escola do Largo de São Francisco!

Egrégia Congregação.

Vós me abristes as portas dêste Santuário. Eu vos abri o coração de professor que tem entusiasmo pelo ensino.

Finalizo minha oração, lembrando a história daquele homem que subia a montanha na qual centenas de trabalhadores quebravam pedras.

Pergunta ao primeiro trabalhador. - Que fazes? "Quebro pedras", foi a resposta.

Mais acima, interroga o segundo trabalhador. - Que fazes? "Ganho o meu pão".

Bem mais acima, a mesma indagação a um terceiro trabalhador. - Que fazes? "Construo uma Catedral".

Ao subir um a um os degraus do magistério, quero poder dar esta terceira resposta, como cada um de vós: "Estamos aqui trabalhando na obra de uma extraordinária e imorredoura Catedral - A Catedral do Direito do Brasil." 